\title{
Kinderwunsch? Täglicher Sex kein Nachteil
}

Oft wird Paaren mit Kinderwunsch in der fruchtbaren Phase Sex höchstens alle zwei Tage empfohlen. Möglicherweise ist der tägliche Koitus aber erfolgreicher. Die Spermienzahl ist dann zwar geringer, dafür haben die Spermien weniger DNA-Schäden.

Urologen um Dr. Ashok Agarwal von der Cleveland Clinic analysierten Samenproben von sieben normozoospermischen Männern mit einem Ejakulationsintervall von ein, zwei, fünf, sieben, neun und elf Tagen. Die Proben erzeugten die Männer per Masturbation im andrologischen Labor der Klinik. Neben einigen Standardparametern (Spermienzahl und -dichte, Viskosität, Vitalität und Morphologie) bestimmten die Forscher um Agarwal auch die Konzentration reaktiver Sauerstoffspezies im
Samen sowie die DNA-Fragmentierung in den Spermien.

Warteten die Männer zwei Tage bis zur nächsten Ejakulation, dann war das Samenvolumen um 27\% höher als nach einem Tag, elf Tage später betrug der Unterschied 87\%. Die Spermienzahl lag nach elf Tagen rund dreifach höher als nach einem Tag.

Die DNA-Fragmentierung stieg jedoch mit der Zeit kontinuierlich an: Mit ein bis zwei Tagen Abstinenz ließen sich größere DNA-Schäden nur bei rund $10 \%$ der Spermien nachweisen, nach fünf Tagen lag der Anteil bei 12\% und nach elf Tagen bei $20 \%$.

mut

- Agarwal A et al. Urology 2016, online 16. Mai; doi: 10.1016/j. urology.2016.03.059

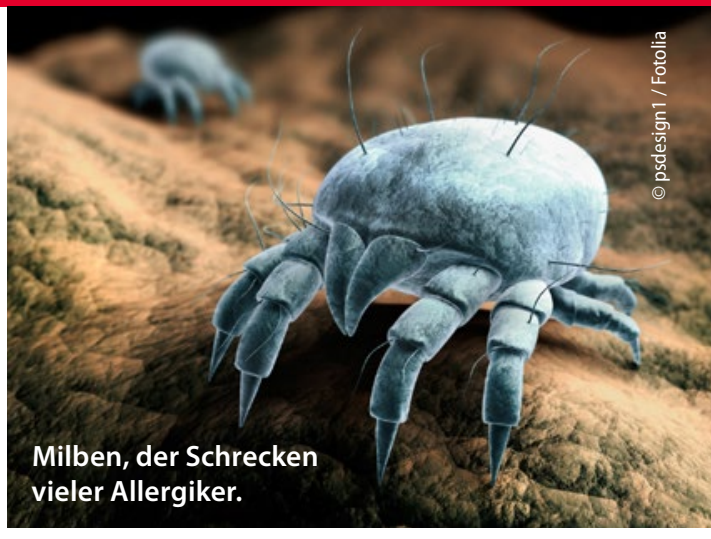

Hausstaubmilben-Allergie

\section{Mit SLIT weniger Asthmaanfälle}

Asthmatiker, die an einer Hausstaubmilbenallergie leiden, profitieren von einer sublingualen Immuntherapie (SLIT), wie eine Studie der Universität Rostock ergeben hat. Bei 742 Teilnehmern wurde die einmal tägliche Einnahme zweier unterschiedlich dosierter SLIT-Tabletten (6 SQ-HDM [n = 237] und 12 SQ-HDM [ $=248]$ ) im Vergleich zu Placebo $(n=257)$ getestet.

Am Studienende hatte sich in beiden SLIT-Gruppen das Risiko für eine Asthmaexazerbation im Vergleich zur Placebogruppe um etwa $30 \%$ verringert. Schwere systemische Reaktionen auf die Hyposensibilisierung wurden nicht berichtet. - JAMA 2016;315(16):1715-1725

\section{Psoriasispatienten auf erektile Dysfunktion screenen?}

Männer mit Psoriasis sollten chinesischen Forschern zufolge routinemäßig nach Erektionsstörungen (ED) befragt werden. Patienten, bei denen beides zusammentrifft, sind offenbar Risikokandidaten für kardiovaskuläre Erkrankungen und Depressionen.

191 Psoriasispatienten wurden mit ebenso vielen hautgesunden Teilnehmern verglichen. In der Gruppe der Psoriatiker litten $52,9 \%$ unter $\mathrm{ED}$, in der Vergleichsgruppe waren es 40,3\%.

Im Vergleich zur Kontrollgruppe zeigten sich bei Männern mit Psoriasis häufiger Hypertonie (33,5\% vs. 19,9\%), Hyperlipidämie (32,5\% vs. 23,6\%) und Diabetes (11,5\% vs. $5,2 \%)$. Die Wahr- scheinlichkeit einer ED war bei den Psoriatikern mit Bluthochdruck um den Faktor 2,79 erhöht, bei Vorliegen einer Hyperlipidämie um den Faktor 2,47. Auch Depressionen wawren bei den Patienten mit Psoriasis mit dem Auftreten von Erektionsstörungen assoziiert.

Man geht heute davon aus, dass die ED den kardiovaskulären Symptomen i.d.R. zwei bis drei Jahre vorausgeht. Die frühe Diagnose einer ED könnte ein wertvoller Hinweis auf drohende kardiovaskuläre Probleme sein.

- Ji S et al. International Journal of Impotence Research 2016. 28:96-100; doi: 10.1038/ijir.2016.6

\section{Momentum Projekt Heidelberg}

Im Rahmen des von der Deutschen Krebshilfe geförderten Momentum Projektes Heidelberg läuft derzeit eine Befragung zum Thema "Aktiver Umgang mit einer Krebserkrankung". Teilnehmende Ärzte werden dabei zu Maßnahmen befragt, die sie Krebspatienten zusätzlich zur medizinischen Behandlung empfehlen, z. B. ernährungsbezogene Strategien oder körperliche Aktivität.

Zur Online-Befragung geht es unter www.momentum-projekt.de. Alternativ können Sie bei momentum@dkfz.de den Fragebogen in einer Papierversion anfordern. Teilnehmer erhalten eine Aufwandsentschädigung in Höhe von $25 €$. 